\title{
Fatigue Resistance of Bituminous Mixtures and Mortars Containing High Reclaimed Asphalt Content
}

\author{
Alexandros Margaritis ${ }^{1,2}{ }^{\mathbb{D}}$, Geert Jacobs ${ }^{1}\left(\mathbb{D}\right.$, Georgios Pipintakos $^{1}{ }^{\mathbb{D}}$, Johan Blom ${ }^{1}(\mathbb{C}$ \\ and Wim Van den bergh $1, *$ (D) \\ 1 EMIB Research Group, University of Antwerp, 2020 Antwerp, Belgium; \\ alexandros.margaritis@uantwerpen.be (A.M.); geert.jacobs@uantwerpen.be (G.J.); \\ georgios.pipintakos@uantwerpen.be (G.P.); johan.blom@uantwerpen.be (J.B.) \\ 2 Belgian Road Research Center, 1200 Brussels, Belgium; a.margaritis@brrc.be \\ * Correspondence: wim.vandenbergh@uantwerpen.be
}

Received: 3 November 2020; Accepted: 7 December 2020; Published: 12 December 2020 updates

\begin{abstract}
With the increased use of reclaimed asphalt (RA), the ability of bituminous materials to resist fatigue cracking may face a decline mainly due to the aged reclaimed asphalt binder (RAB), especially when RA is used at higher rates and not sufficiently treated. In this study, the bulk scale (asphalt) and its subscale (mortar) were employed to evaluate the effect on fatigue resistance when a $\mathrm{RAB}$ is added, by considering three replacement rates: $0 \%, 40 \%$, and $70 \% \mathrm{RAB}$. The fatigue testing of asphalt mixtures was carried out using a four-point bending (4PB) setup, while the mortars were tested using a new column-like geometry utilising a dynamic shear rheometer (DSR). The fatigue properties were further analysed using dissipated energy concepts. The aim of this study was, first, to assess whether the inclusion of a RAB can provide at least similar fatigue properties compared to an all-virgin mix, and second, to evaluate whether the proposed treatment is beneficial for the mixtures with a RAB. The asphalt tests revealed that the inclusion of a $40 \%$ RAB led to increased fatigue resistance, whereas the mortar tests showed that the inclusion of RAB has an inverse effect on fatigue life.
\end{abstract}

Keywords: reclaimed asphalt; bituminous mortar; asphalt; fatigue resistance; dynamic shear rheometer; four-point bending; dissipated energy

\section{Introduction}

At present, asphalt recycling is prevalent within the road construction industry because it is accepted as a sustainable approach. Although the economic and environmental benefits of using reclaimed asphalt (RA) are widely accepted, questions arise from the construction sector concerning the service life of asphalt mixtures with RA. In Belgium, the current average content of RA in new mixtures is $40 \%$, and this is almost exclusively used in dense-graded asphalt mixtures for base layer applications [1]. According to recent studies, this RA content appears to perform reasonably well in the lab and has a good environmental impact [1,2], but there is certainly the potential to go higher in terms of recycling rates.

Concerning the effect of RA on the performance of asphalt mixtures, one of the main engineering problems associated with the inclusion of RA in base layer asphalt mixtures is fatigue cracking [3-6]. One of the most critical distress types for asphalt pavements is cracking. The focus of this study will be on the cracking done at intermediate temperatures or also known as fatigue cracking. This type of cracking initiates when excessive tensile strains develop at the bottom of the asphalt layer leading to crack initiation [7]. 
In the US, many studies have been performed concerning the field performance of mixtures containing RA. In 1991, the FHWA initiated the Long-Term Pavement Performance (LTPP) programme, which provided valuable results based on field performance observations [8,9]. Overall, it was concluded that the addition of up to $30 \%$ RA did not alter the performance of mixtures significantly. In a project conducted by the California Department of Transportation, it was concluded that after five years of service, no difference was observed between the virgin and recycled mixtures (15\% RA) [10]. Generally, the abovementioned field results can be considered reasonable, taking into account the rather conservative recycling rate, with the highest being $30 \%$.

Several studies have attempted to evaluate the effect of high RA, i.e., above $40 \%$, in the lab. Some lab-based studies showed a positive effect of RA, with some indicative examples being the studies of Al Qadi (up to 50\% RA) and McDaniel (up to 40\% RA) [5,11]. Margaritis et al. statistically analysed fatigue results of 74 lab-tested mixtures, used in Flanders. The results showed that mixtures with RA (up to $60 \%$ RA) exhibited similar fatigue properties compared to virgin mixtures [1]. Furthermore, Sabouri et al. concluded that the inclusion of $40 \%$ RA led to reduced resistance in fatigue cracking [12]. A study by Mangiafico et al. showed that fatigue resistance was higher for mixtures with RA from $20 \%$ until $40 \%$ and that for mixtures with $60 \%$, a small drop was observed, concluding that the optimum percentage in terms of fatigue resistance is between $20 \%$ and $40 \%$ [13].

Typically when fatigue is evaluated in the lab, the focus is on the bulk scale, i.e., the asphalt mixture. Over the years, many studies have experimentally evaluated certain mechanical responses, such as fatigue, not only in the bulk scale but also in the subscales, such as the mortar scale, which represents the mesoscale. This phase is crucial for the bituminous mixture, as two failure types will initiate from it, namely cohesive and adhesive failure. Testing bituminous materials in a subscale is not uncommon. Fatigue tests in the binder scale are very typical for benchmarking and classifying different bituminous binders. Moreover, testing bituminous mastics (bitumen and filler) has also been widely used, and this has the advantage of including the filler, where different filler types can greatly influence their fatigue behaviour [14,15]. The mortar scale also allows for the inclusion of sand (the whole fraction or part of it), which has been demonstrated to play a significant role in the bituminous coating and the bonding of the coarse aggregate skeleton [16,17].

\section{Objectives and Scope}

To assess the true effect of RA, it is necessary to evaluate mixtures with very similar mix design and binder properties. The primary objectives of this paper were two-fold. The first is to assess whether the inclusion of RA can provide at least similar fatigue properties compared to an all-virgin mortar and asphalt mix. The second is to evaluate whether adding only the virgin binder, without the use of other recycling agents, is beneficial for the mixtures with RA. In this study, three mixtures with $0 \%, 40 \%$, and $70 \%$ reclaimed asphalt binder (RAB) are designed and evaluated. Asphalt beams are tested using a four-point bending (4PB) setup and column-like mortar samples using a dynamic shear rheometer (DSR). The results are analysed using conventional criteria and fundamental energy concepts.

\section{Materials}

To evaluate the effect of $\mathrm{RAB}$ on the fatigue resistance, three asphalt concrete mixtures with a nominal maximum aggregate size of $14 \mathrm{~mm}$ (AC14 or APO-B according to the Flemish road regulations) were theoretically designed by considering three replacement rates: $0 \%, 40 \%$, and $70 \%$ RAB. The RA was provided by a local asphalt plant, and it is a homogeneous (milled from a single road source), continuous graded $0 / 14 \mathrm{~mm}$ asphalt mixture with a $5.18 \%$ binder content (on mixture mass). The RAB has a penetration of $240.1 \mathrm{~mm}$ and a softening point of $63^{\circ} \mathrm{C}$, measured based on EN 1426 and EN 1427 [18,19], accordingly. More information on the chemical and rheological properties of the RAB can be found in a previous study [20], where the RAB is denoted as the RA18 sample.

The gradation of the three mortars was derived from the corresponding asphalt mixtures. The mix design of the bituminous mortars and mixtures was similar in terms of aggregate gradation and binder 
blend penetration, contingent upon the assumption of full blending, a representative of the standard practice which, however, may not be valid as demonstrated by previous studies.

All asphalt mixtures were designed theoretically using the design software PradoWin (Belgian Road Research Centre, Brussels, Belgium), based on a typical design of an AC14 mixture used in Flanders. The mixtures were designed with a theoretical binder content of $4.3 \%$ on aggregate mass $(4.12 \%$ on mixture). The gradation curves of the mixtures and mortars are presented in Figure 1. The fractional composition of the bituminous mortars and mixtures is given in Table 1. Furthermore, the maximum density was calculated according to EN 12697-5 [21], and then, for the tested asphalt beams, the air voids were estimated while considering the volumetric estimation of the bulk density. The maximum density and the average air voids of the three asphalt mixes are presented in Table 2.

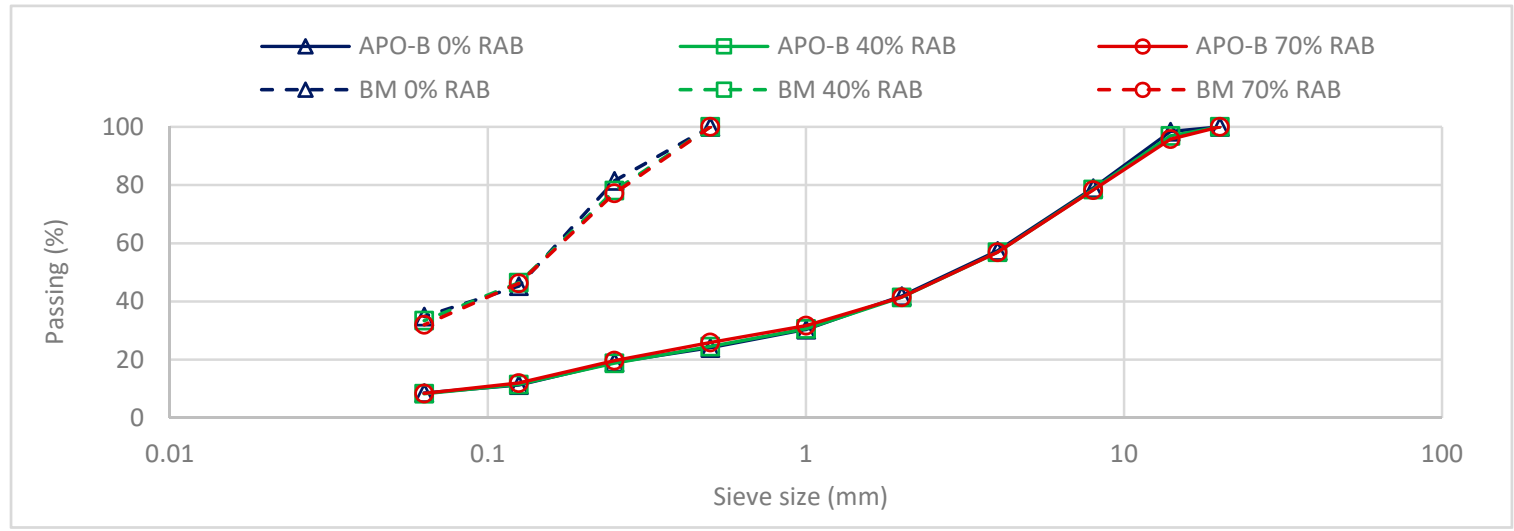

Figure 1. Particle size distribution of the bituminous mortar (BM) and asphalt mixture (APO-B) designs for the three reclaimed asphalt binder (RAB) replacement rates: $\%, 40 \%$, and 70\% RAB.

Table 1. Fractional composition of the three bituminous mortar and APO-B mixtures for the three replacement rates: $0 \% \mathrm{RAB}, 40 \% \mathrm{RAB}$, and $70 \% \mathrm{RAB}$.

\begin{tabular}{|c|c|c|c|c|c|c|}
\hline- & \multicolumn{3}{|c|}{ Bituminous Mortar (BM) $(<0.5 \mathrm{~mm})$} & \multicolumn{3}{|c|}{ Asphalt Mixture (APO-B) } \\
\hline Component & $\begin{array}{c}\text { BM } 0 \% \text { RAB } \\
(\%)\end{array}$ & $\begin{array}{c}\text { BM 40\% } \\
\text { RAB } \\
(\%)\end{array}$ & $\begin{array}{c}\text { BM 70\% } \\
\text { RAB } \\
\text { (\%) }\end{array}$ & $\begin{array}{c}\text { APO-B 0\% } \\
\text { RAB } \\
\text { (\%) }\end{array}$ & $\begin{array}{c}\text { APO-B 40\% } \\
\text { RAB } \\
(\%)\end{array}$ & $\begin{array}{c}\text { APO-B 70\% } \\
\text { RAB } \\
\text { (\%) }\end{array}$ \\
\hline Limestone 6.3/14 & - & - & - & 26.29 & 15.84 & 7.97 \\
\hline Limestone $2 / 6.3$ & - & - & - & 27.62 & 23.45 & 20.49 \\
\hline Limestone $0 / 2$ & 25.83 & 20.56 & 15.06 & 26.25 & 20.92 & 15.84 \\
\hline Riversand 0/1 & 20.16 & 7.11 & 1.20 & 6.56 & 2.32 & 0.40 \\
\hline RA $0 / 14$ & - & 20.73 & 34.61 & - & $29.48^{* 1}$ & $50.88^{* 1}$ \\
\hline RA Filler & - & 8.88 & 14.83 & - & - & - \\
\hline $\begin{array}{l}\text { Filler (type } \\
\text { V28/38) }\end{array}$ & 28.41 & 17.10 & 9.56 & 9.16 & 5.51 & 3.18 \\
\hline Bitumen & 25.61 & 25.59 & 24.74 & 4.12 & $2.47^{* 2}$ & $1.24^{* 2}$ \\
\hline Total & 100.00 & 100.0 & 100.00 & 100.00 & 100.00 & 100.00 \\
\hline
\end{tabular}

Table 2. Volumetric properties of the asphalt mixes.

\begin{tabular}{|c|c|c|}
\hline Mixture & $\begin{array}{c}\text { Maximum Density } \\
\left(\mathrm{g} / \mathrm{m}^{3}\right) \\
\text { EN 12697-5 }\end{array}$ & $\begin{array}{c}\text { Air Voids } \\
\left(\begin{array}{c}(\%) \\
\text { EN } 12697-8\end{array}\right.\end{array}$ \\
\hline APO-B $0 \%$ RAB & 2499.1 & $4.2( \pm 0.9)$ \\
\hline APO-B $40 \%$ RAB & 2488.6 & $4.0( \pm 0.7)$ \\
\hline APO-B 70\% RAB & 2482.3 & $5.0( \pm 0.8)$ \\
\hline
\end{tabular}


The production of asphalt mixtures was carried out following the EN 12697-35:2016 [22]. For the 40 and $70 \%$ RAB mortar mixtures, the RAB was extracted and recovered and consequently mixed with virgin binders, providing the necessary binder blends for the mortar mixtures. It must be noted here that the used mortar composition of this study followed an enriched composition, which is necessary to achieve a workable and thus self-compactable mortar mix. An enriched composition means that the mortar mixtures have more bitumen than the actual mortar phase in the bulk. The procedure to calculate the enriched composition, as well as the fabrication steps of mortar mixes, are elaborately discussed and presented in a previous study [23]. Finally, it must be noted here that the proposed fabrication method aims to minimise the air voids in the mortar sample. The reason for that is to achieve a homogeneous material and to assess its mechanical performance (i.e., fatigue) without the existence of air cavities within the sample, which may influence the integrity of the sample and thus its fatigue resistance.

To achieve the same binder properties between the mixtures, the binder blend cases were theoretically designed, using the log-pen rule in Equation (1), provided by EN 13108-1 [24]. For the control mixture with $0 \% \mathrm{RAB}$, a 35/50 penetration grade bitumen was used, with a penetration value of $430.1 \mathrm{~mm}$. The penetration of the control virgin binder was used as the base for the second and third binder blends, i.e., 40\% RAB and 70\% RAB, respectively, and it was developed using Equation (1). To achieve the exact same penetration, two new artificial binder blends were developed for the $40 \%$ and $70 \%$ RAB mix, namely a hard blend (HB) and soft blend (SB), respectively. The exact compositions are presented in Tables 3 and 4. Furthermore, the measured penetration and the softening point of the final binder blends are presented in Table 3.

$$
\mathrm{a} \log \left(\text { pen }_{\text {virgin }}\right)+\mathrm{b} \log \left(\text { pen }_{\mathrm{RAB}}\right)=\log \left(\text { pen }_{\text {mix }}\right)
$$

Table 3. Theoretical binder mix design and measured conventional properties of the final binder blends.

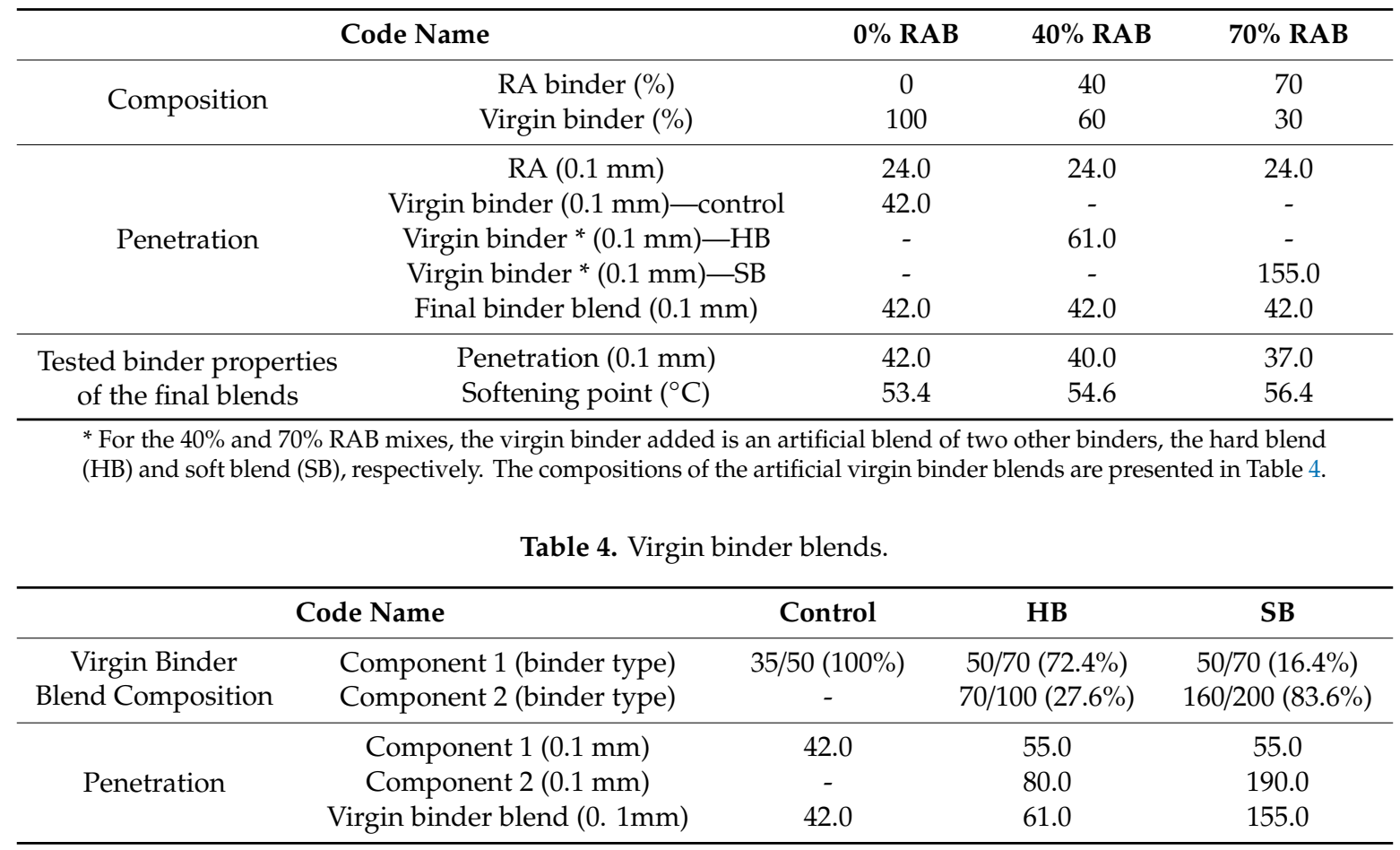

Factors $\mathrm{a}$ and $\mathrm{b}$ are the proportions of the two components $(\mathrm{a}+\mathrm{b}=1)$; pen $_{\text {virgin, }}$, pen $_{\mathrm{RAB}}$, and pen $\mathrm{n}_{\text {mix }}$ are the penetration values of the virgin binder component, the RAB component, and the final binder blend mix, respectively. 


\section{Experimental Investigation}

\subsection{Fatigue Testing}

The asphalt fatigue tests were performed using the 4-point bending (4PB) setup, and the mortar tests were done using a DSR (see Figure 2). Two key parameters were defined for all three mixtures, i.e., their stiffness modulus and fatigue resistance. Both tests were performed using the $4 \mathrm{~PB}$ testing setup, as described in EN 12697-26:2018 (Annex B) and EN 12697-24:2018 (Annex D), respectively [25,26]. To define the $\left|E^{*}\right|$ modulus, cyclic tests were performed at $15{ }^{\circ} \mathrm{C}$, and their total duration was set for approximately $1 \mathrm{~min}$, per frequency step $(0.1$ to $20 \mathrm{~Hz})$. The fatigue tests were performed under a strain-control mode, between 85 and $145 \mu \mathrm{m} / \mathrm{m}$, at $15^{\circ} \mathrm{C}$, and $30 \mathrm{~Hz}$. For the fatigue characterisation of each mixture, at least 3 replicates were tested at a minimum of 3 strain levels, with the total number of replicates ranging from 11 to 15 .

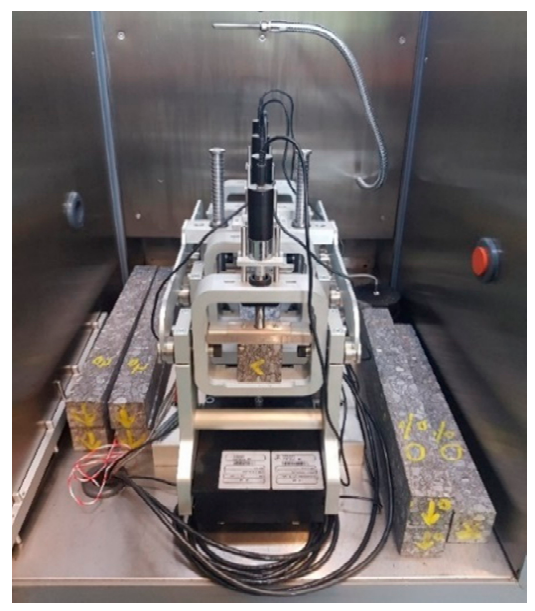

(a)

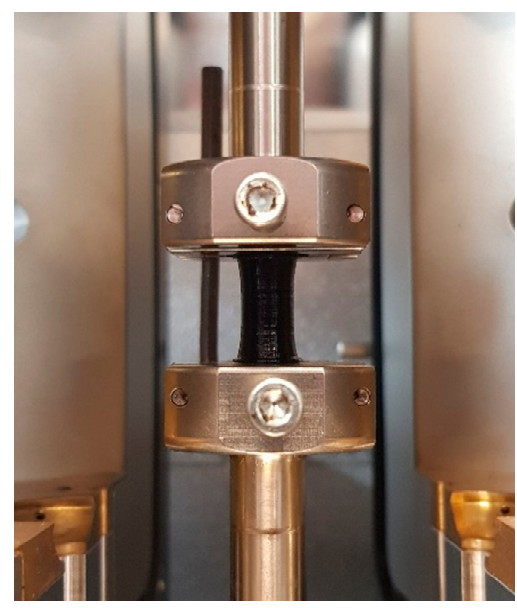

(b)

Figure 2. Four-point bending (4PB) testing setup for the asphalt mixtures (a) and clamping of the bituminous mortar inside the dynamic shear rheometer (DSR) temperature chamber (b).

For the evaluation of the fatigue resistance of bituminous mortars, a newly proposed sample geometry was utilised [23]. The mortar sample geometry consists of three parts, namely two half one-sheeted hyperboloids, both approaching the diameter of a cylindrical middle part. The mortar samples were tested using torsional time-sweep tests in an oscillatory mode, and the measurements were performed until the complete failure of the specimen. The performed torsional tests were stress-controlled and not strain-controlled since stress is typically more accurately and faster achieved, given that most DSR devices are torque-controlled. The stress levels were selected with the purpose of keeping them outside of the linear viscoelastic region (LVER). This was the case for both asphalt and mortar fatigue tests. Therefore, the mortar mixtures were tested using stress amplitudes between 0.85 and $1.40 \mathrm{MPa}$, and the tests were performed at $15^{\circ} \mathrm{C}$ and $10 \mathrm{~Hz}$. For each mortar mix, 17 to 24 samples were tested. More information concerning the fatigue testing framework, the used geometry, and fabrication procedure are presented in a previous study [23].

\subsection{Fatigue Resistance Analysis: Conventional and Energy Concepts}

The fatigue resistance of the tested asphalt mixtures was further analysed based on two approaches: using the empirical failure criterion $\mathrm{N}_{\mathrm{f} 50}$ and using energy approaches. The energy concepts are based on the fundamental response of the material when sustaining external loading. During cyclic loading, two curves are generated on a stress-strain plot, representing the loading and unloading phase of the material. This plot is also known as the hysteresis loop, and its area provides the dissipated energy (DE) per cycle, which can be approximated using Equation (2). 
Many energy concepts that make use of the DE approach have been introduced. The method that is possibly the least unbiased one is the ratio of dissipated energy change (RDEC). The RDEC approach was introduced to provide a better approximation of the actual damage, taking into account only the DE change between the cycles $[27,28]$. RDEC can be calculated using Equation (3). When the RDEC is plotted against the loading cycles, a plateau energy stage can be observed. This plateau stage expresses a unique energy parameter, namely the plateau value (PV). It has been demonstrated that the PV exhibits an excellent relationship with the $\mathrm{N}_{\mathrm{f5}}$, which is independent of temperature effect, material properties, and loading mode [28,29].

$$
\begin{gathered}
\mathrm{w}_{\mathrm{i}}=\pi \sigma_{\mathrm{i}} \varepsilon_{\mathrm{i}} \sin \left(\delta_{\mathrm{i}}\right) \\
\operatorname{RDEC}_{\mathrm{b}}=\frac{\mathrm{w}_{\mathrm{b}}-\mathrm{w}_{\mathrm{a}}}{\mathrm{w}_{\mathrm{a}}(\mathrm{b}-\mathrm{a})}
\end{gathered}
$$

where $\varepsilon$ is the strain $(\mathrm{m} / \mathrm{m}) ; \sigma$ is the normal stress $(\mathrm{kPa}) ; \delta$ is the phase angle $\left({ }^{\mathrm{o}}\right) ; \mathrm{w}_{\mathrm{i}}$ is the dissipated energy per cycle $I\left(\mathrm{kj} / \mathrm{m}^{3}\right)$; $a$ and $b$ are cycles with $b>a ; R C_{b}$. is the ratio of dissipated energy change at cycle $b$ during a cycle period of $b-a$ cycles; and $w_{a}$ and $w_{b}$. are the dissipated energies at cycles $a$ and $b$, respectively.

For the mortar fatigue assessment, the phenomenological approach $\mathrm{N}_{\mathrm{f}, \mathrm{G}^{*} \mathrm{xC}}$ was used first to assess the fatigue resistance of the mortar. The phenomenological failure was estimated by plotting the product of $\mathrm{G}^{*}$ and cycles against cycles, and then a distinctive maximum point was observed $\left(\mathrm{N}_{\mathrm{f}, \mathrm{G}^{*} \times \mathrm{C}}\right)$ [30]. In addition to the $\mathrm{N}_{\mathrm{f}, \mathrm{G}^{*} \times \mathrm{C}}$ approach, two energy concepts were also considered: the dissipated energy ratio (DER) and the RDEC concept. For the DER approach, fatigue was derived between the $\mathrm{N}_{\mathrm{p} 20}$ (i.e., the moment where the DER deviates more than $20 \%$ from the linear viscoelastic state) and the $\mathrm{W}_{0}$, the initial DE. For the mortar samples, the DE per cycle was calculated using Equation (2), taking into account the shear stress $(\tau)$ instead of the normal stress $(\sigma)$. In a previous study, it was demonstrated that the energy parameter PV correlated well with all failure moments $\mathrm{N}_{\mathrm{f} 50 \text {, }}$ $\mathrm{N}_{\mathrm{f}, \mathrm{G}^{*} \mathrm{xC}}$, and $\mathrm{N}_{\mathrm{p} 20}$, which provided a unique fatigue model, with the best fit being achieved for the model between $\mathrm{PV}$ and $\mathrm{N}_{\mathrm{p} 20}$ [23].

One of the discouraging points of the RDEC approach is the rather challenging estimation of the PV value. Carpenter and Shen defined an equation, based on which the PV can be estimated [28]. First, a power fit must be established between the $\mathrm{DE}$ and loading cycles (LC): $\mathrm{DE}=\alpha \mathrm{LC}^{\mathrm{f}}$, with a and $\mathrm{f}$ being the regression coefficients of the fit. Based on the slope $f$ and the $N_{f 50}$ of the tested sample, the PV can be estimated. However, fitting a power fit is not always successful, as previously stated also by Subhy et al. [31], and therefore calculating the PV with the formula Shen and Carpenter proposed is not always feasible. To counteract for this issue, the following methodology is proposed to extract a more reliable PV. First, by visual inspection, PV is defined by checking in which RDEC phase (II or III) the $\mathrm{N}_{\mathrm{f50}}$ falls in. Then, if the $\mathrm{N}_{\mathrm{f} 50}$ falls within phase II, the PV is calculated as the average RDEC of the 10 last points before $\mathrm{N}_{\mathrm{f} 50}$. If $\mathrm{N}_{\mathrm{f} 50}$ falls in phase III, then the PV is calculated by taking the 10 average RDEC points before the midlife point of $\mathrm{N}_{\mathrm{f} 50}\left(0.5 \times \mathrm{N}_{\mathrm{f} 50}\right)$, which for all tested samples fell in phase II.

As an example, three PV values were calculated and presented in Figure 3. First, the PV was estimated using the Carpenter and Shen equation (PV@EQ). Then, the PV was calculated from the average of 10 RDEC points before $\mathrm{N}_{\mathrm{f} 50}\left(\mathrm{PV} @ \mathrm{~N}_{\mathrm{f} 50}\right)$, and finally, the average of 10 RDEC points before $0.5 \times \mathrm{N}_{\mathrm{f} 50}$ was used for PV (PV@ $\left.\mathrm{N}_{\mathrm{f} 50 / 2}\right)$. For this sample, the $\mathrm{N}_{\mathrm{f} 50}$ fell within phase III. Consequently, the PV@ $\mathrm{N}_{\mathrm{f} 50}$ seems to be overestimated $\left(3.0 \times 10^{-6}\right)$, since phase III has already started, and the RDEC values are increased. In contrast, the PV@EQ is underestimated $\left(4.0 \times 10^{-8}\right)$, being at the same level as some (very few) RDEC points, which seem to be more like outliers. Finally, the ${\mathrm{PV} @ \mathrm{~N}_{\mathrm{f} 50 / 2}}$ $\left(4.9 \times 10^{-6}\right)$ is right within the cloud of data points of the plateau stage, indicating that it is a more appropriate estimation. 


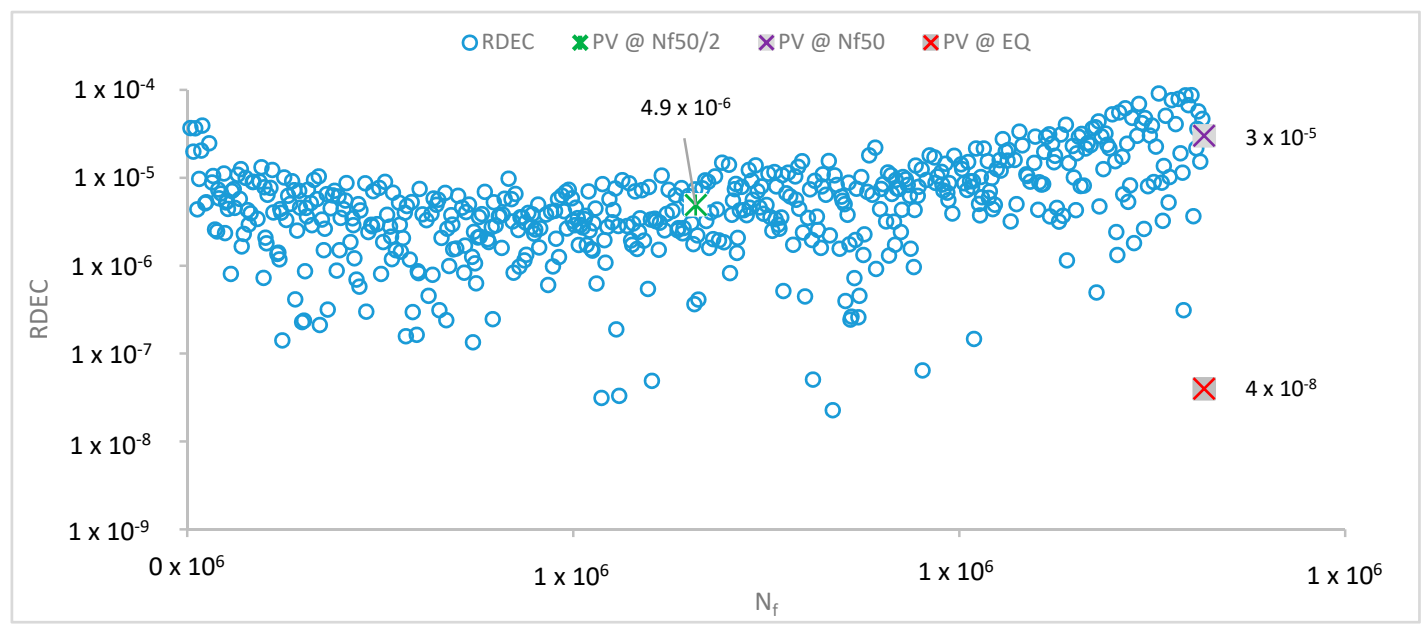

Figure 3. Estimation of the plateau value (PV) using the ratio of dissipated energy change (RDEC) plot against the loading cycles.

\section{Results and Discussion}

\subsection{Bituminous Mixtures}

The $\left|\mathrm{E}^{*}\right|$ modulus of the 3 mixtures at $15^{\circ} \mathrm{C}$ and at a frequency range from 0.1 to $20 \mathrm{~Hz}$, is illustrated in Figure 4. Starting at the lowest tested frequency $(0.1 \mathrm{~Hz})$, the mixtures with RAB showed a slightly higher $\left|\mathrm{E}^{*}\right|$, and at $0.2 \mathrm{~Hz}$ the $\left|\mathrm{E}^{*}\right|$ was similar among the 3 mixtures. Above that frequency point, the mixtures with $R A B$ showed a gradually small decrease in $\left|E^{*}\right|$, as frequency increased. It can be observed that the $70 \%$ RAB mix shows the highest deviation compared with the rest, and this can be attributed to the high replacement rate, which induces a certain variability. Nevertheless, the observed small differences cannot be characterised as significant since there are overlapping standard deviations, and thus it can be concluded that the three mixtures demonstrate a similar $\left|E^{*}\right|$ modulus. These results are rather expected since the gradation and the binder penetration are similar, at least theoretically, as well as the average air voids of the asphalt beams. Therefore, the addition of RA seems to not have an influence on the $\left|\mathrm{E}^{*}\right|$ modulus of the studied mixtures.

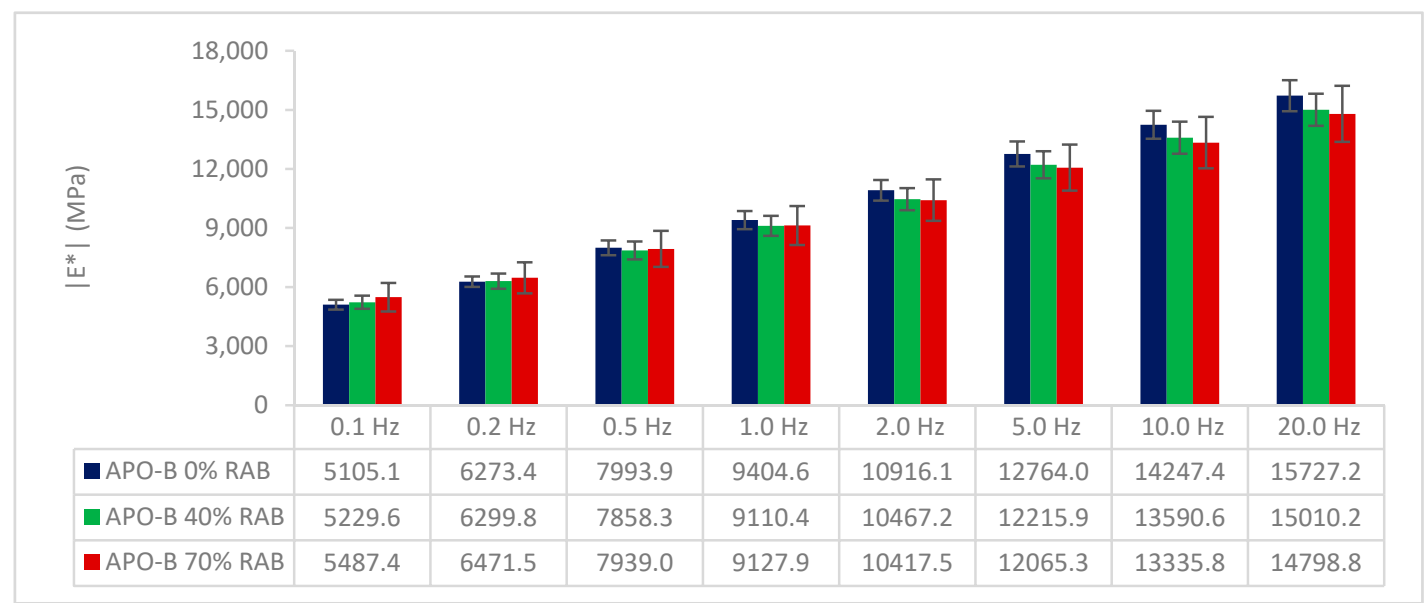

Figure 4. $\left|E^{*}\right|$ modulus of the three mixtures under various frequencies.

To assess the effect of RAB inclusion on the fatigue resistance of dense-graded asphalt mixtures, both conventional and energy criteria were considered. The fatigue life can be depicted using the Wöhler curves, where the applied strain is plotted against the cycles until failure $\left(\mathrm{N}_{\mathrm{f}}\right)$. The fatigue curves are presented in Figure 5, and the parameters of the fatigue curves are described in Table 5. 


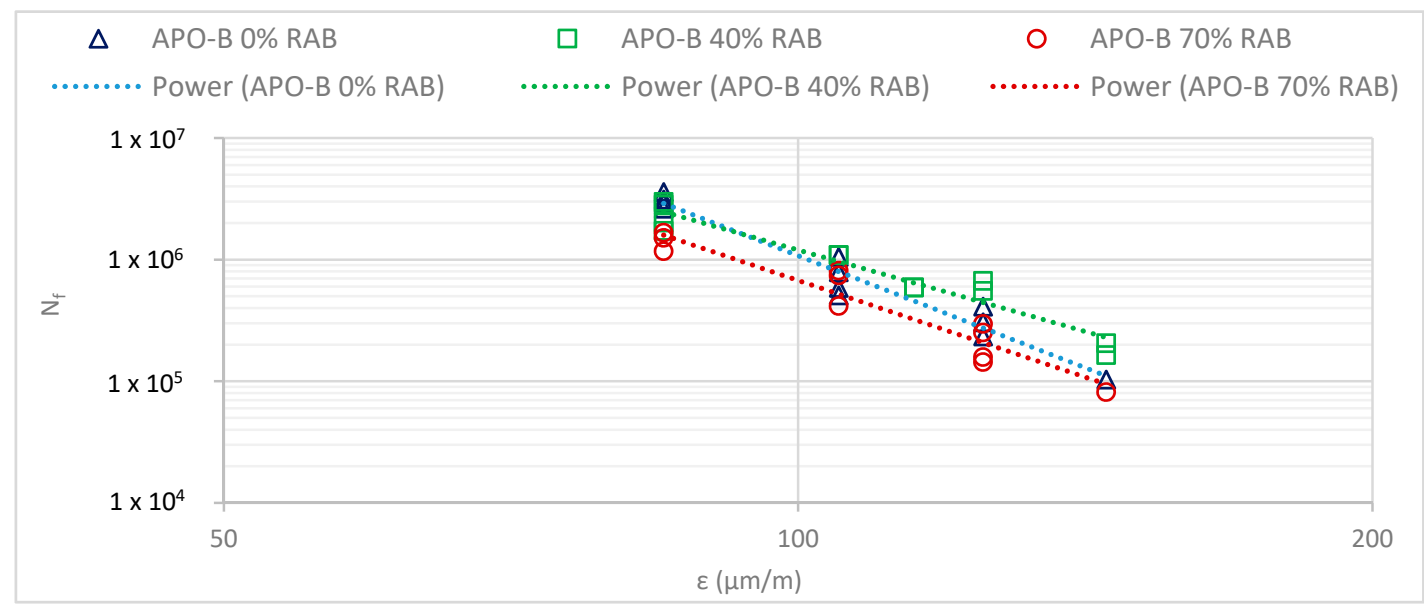

Figure 5. Fatigue curves (Nf50) of the three asphalt mixtures.

Table 5. Fatigue test parameters for the asphalt mixtures.

\begin{tabular}{cccccc}
\hline $\mathbf{N}_{\mathbf{f}, 50}=\mathbf{A}(\varepsilon)^{\mathbf{B}}$ & $\mathbf{A}$ & $\mathbf{B}$ & $\begin{array}{c}\mathbf{R}^{\mathbf{2}} \\
\mathbf{( \% )}\end{array}$ & $\begin{array}{c}\varepsilon_{6} \\
(\mu \mathbf{m} / \mathbf{m})\end{array}$ & $\begin{array}{c}\varepsilon_{5} \\
(\mu \mathbf{m} / \mathbf{m})\end{array}$ \\
\hline APO-B 0\% RAB & $2 \times 10^{8}$ & -6.121 & 95.62 & 102 & 145 \\
APO-B 40\% RAB & $2 \times 10^{15}$ & -4.452 & 93.66 & 104 & 170 \\
APO-B 70\% RAB & $2 \times 10^{16}$ & -5.282 & 91.78 & 94 & 140 \\
\hline
\end{tabular}

The $\varepsilon_{6}$ parameter represents the strain level at which the fatigue life is $10^{6}$ cycles and is widely used as a fatigue resistance parameter. A higher $\varepsilon_{6}$ indicates a higher fatigue life. For this study, the $40 \%$ RAB mix exhibited the highest fatigue resistance, followed by the $0 \%$ RAB mix. The mixture with the $70 \% \mathrm{RAB}$ showed the lowest fatigue resistance. These findings are in line with previous studies that have stated that with up to a $40 \%$ RA inclusion, the fatigue resistance is expected to be higher and then a turning point occurs, above which the trend is different [13].

However, $\varepsilon_{6}$ is only a single point, which may not provide a universal fatigue ranking among the mixtures, since in reality, different strain levels may appear at the bottom of the base asphalt layer. Taking a different strain level as an example, i.e., the $\varepsilon_{5}$ point, the $40 \%$ RAB mix still shows the best performance but with a substantially larger difference compared to the second-best mixture, the $0 \%$ RAB. At the $\varepsilon_{6}$ point, the difference in strain level between the two mixtures $(0 \%$ and $40 \% \mathrm{RAB})$ was only $2 \mu \mathrm{m} / \mathrm{m}$, whereas the difference at the $\varepsilon_{5}$ point was $35 \mu \mathrm{m} / \mathrm{m}$. This points out the significance of taking into account the slope of the fatigue curve also.

The three mixtures tested in this study exhibited different fatigue slopes, with the $0 \%$ RAB mix having the steepest fatigue life slope. Contrary to this investigation, a number of previous studies have reported that ageing will lead to steeper slopes [32], as well as the inclusion of RA, which will lead to similar results (50\% RA) [33]. Other studies have reported similar slopes between all-virgin mixes and mixes containing RA (up to $40 \%$ RA) [12,34]. Mangiafico et al. claimed that when the two binder parts, i.e., $\mathrm{RAB}$ and virgin, have a similar penetration, the slope of the fatigue mixture will not be influenced significantly [35]. Based on this statement and considering the similar theoretical penetration between the blends in this study, it is possible that the fatigue slopes in Figure 5 were influenced by the presence of softer binder zones or thinner binder coating for some aggregates (possibly the virgin aggregates).

As it is evident, the selection of the virgin bitumen and the RAB content will significantly affect the fatigue properties [1]. The findings of the fatigue investigation point out the possible existence of a "softer" binder blend, which is apparent for the 70\% RAB mix. This was not the case for the stiffness measurements, where the $\left|\mathrm{E}^{*}\right|$ was similar among the mixtures. It is, however, possible that the inclusion of RA led to heterogeneous zones within the mixtures, with different binder blend stiffness and binder coverage. These zones are especially crucial during repeated loading (fatigue) since they 
will act as weaker zones. More specifically, the stiffer inactive RAB zones are expected to build higher stress concentration zones that are prone to earlier cracking. The higher the replacement rate, the higher the risk for such zones, especially evident at the $70 \%$ replacement rate. It is likely that by increasing the recycling rate, the risk of having a lower degree of activation is higher. In addition, the inclusion of a very soft virgin binder does not have a beneficial effect on the RAB activation, as demonstrated by the results of the $70 \%$ RAB mix.

In a previous study, it was concluded that the actual bituminous coating of RA is a bituminous mortar, as demonstrated by microscopic images [16]. Commonly for conventional bituminous binders, certain viscosity levels are defined to allow them to adequately mix and cover the aggregates in a bituminous mixture. This viscosity level $(0.17 \pm 0.02 \mathrm{~Pa} \cdot \mathrm{s})$ is achievable at temperatures between 135 and $180^{\circ} \mathrm{C}$ depending on the bitumen type, as described in Table 1 of EN 12697-35:2016 [22]. The viscosity of a field-aged binder is expected to be much higher since it is not a pure bituminous binder but rather a bituminous mortar. Because the preheating temperatures are limited, to avoid further ageing of the RAB, the RA material does not have enough heat capacity to enable its binder. Hence, the use of a rejuvenator is recommended, especially at higher RAB replacement rates (above $50 \%$ ). It has been previously demonstrated that the rejuvenator can act beneficially in the diffusion process between the virgin and aged binder [36,37].

For lean mixtures, meaning low binder content mixtures (like the $70 \%$ RAB mix of this study), there is a considerable risk of ending up with virgin aggregates poorly covered by bitumen. This risk is even higher at high recycling rates, considering the possibility that the RAB activation can be rather low and that the biggest part of the existing bitumen already covers the RA aggregates. This might create a possible weak spot in the mixture at the virgin aggregates since there is not enough bitumen coverage. This problem might be avoided by increasing the total binder content, consequently compensating for the possible inactive RAB. Finally, mixtures containing high RA content should be designed following the performance-based mix design principles, since by adopting this approach, the potential implications of partial blending will be revealed by their effect on the mechanical performance [38].

Besides the conventional failure criterion $\mathrm{N}_{\mathrm{f} 50}$, the fatigue results were analysed using the RDEC approach. Based on the approach described in Section 4.2, the PV was calculated for all tested samples, and then plotted against the $\mathrm{N}_{\mathrm{f} 50}$. The results showed a unified model between the three mixtures (Figure 6). Based on the unified fatigue curve, it is impossible to distinguish and benchmark the three mixtures. For that reason, a different approach that attempts to relate the structural design with the actual fatigue resistance is proposed.

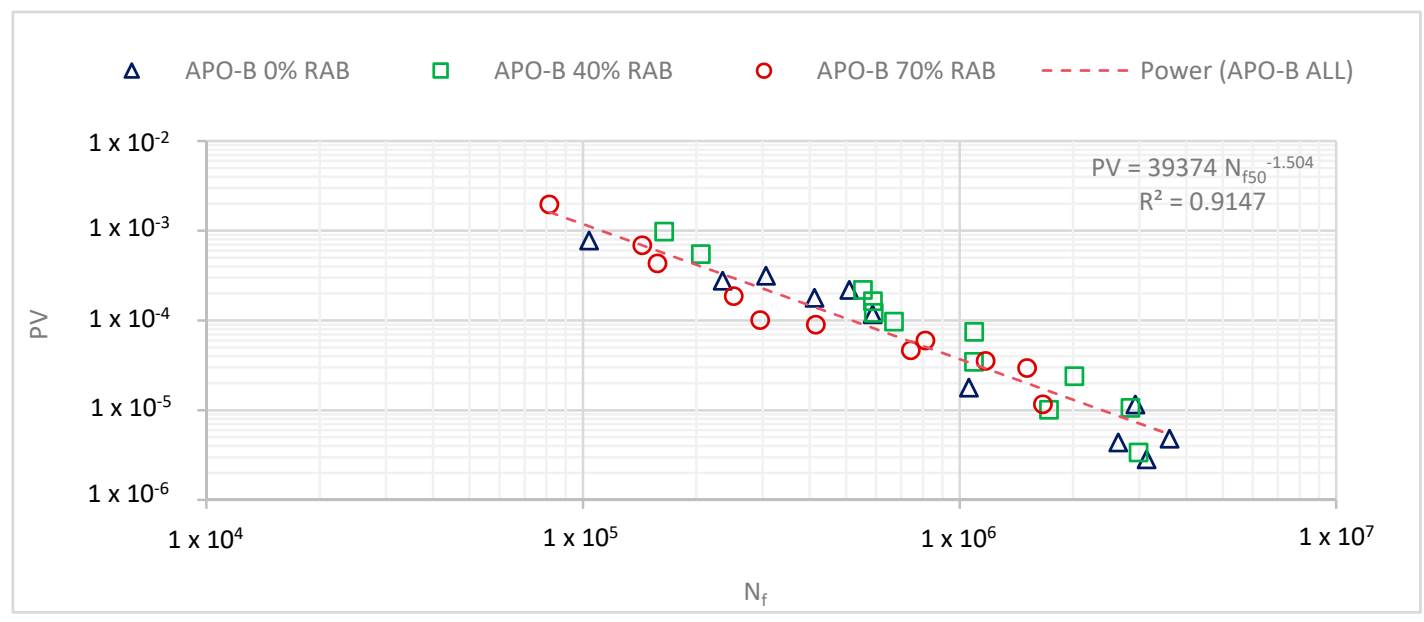

Figure 6. Unified fatigue model for all three mixtures, based on the plateau value (PV) and the loading cycles to failure $\left(\mathrm{N}_{\mathrm{f}}\right)$. 
Typically, during the design process of a pavement structure, the strain levels are estimated at different depths, with a great focus on the bottom side of the asphalt layer, since it is the spot where maximum tensile stress is expected to appear. For this reason, two tested strain levels were selected: 85 and $125 \mu \mathrm{m} / \mathrm{m}$, in an attempt to represent two structural scenarios: a "thicker layer" and "thinner layer" scenario. This is based on the assumption that under the same loading conditions, the two structural scenarios (i.e., thicker and thinner layers) will experience a lower and a higher strain level condition, respectively. Rearranging the power fit from Figure 6, a new fatigue model was derived for the three mixtures that is able to calculate the $\mathrm{N}_{\mathrm{f}}$ for a given PV (Equation (4)). The two strain levels were also selected on the basis that at least three replicates were measured for those two strains.

$$
\mathrm{N}_{\mathrm{f}}=1938.7 \mathrm{PV}^{-0.608} \text {. }
$$

One should note here that all three mixtures have similar $\left|\mathrm{E}^{*}\right|$ at $15^{\circ} \mathrm{C}$ and $10 \mathrm{~Hz}$ (in the range of $13,300-14,200 \mathrm{MPa}$ ), a metric typically requested for design calculations. Additionally, more research is needed to define the representative strain levels for standard layer thicknesses. In this study, to benchmark the materials based on their PV, two strain levels were selected based on a lower and a higher strain level, representing a thicker and a thinner structure.

Based on the defined fatigue life, it is expected that the lower the PV is, the longer the expected fatigue life is. For every PV point, a new $\mathrm{N}_{\mathrm{f}}$ was estimated using Equation (4). The average values of the predicted $\mathrm{N}_{\mathrm{f}}$ are illustrated in Figure 7, per mixture and strain level. Based on the findings, at 85 $\mu \mathrm{m} / \mathrm{m}$, the $0 \%$ RAB mix showed the highest fatigue resistance, whereas at the $125 \mu \mathrm{m} / \mathrm{m}$ level, the $40 \%$ $\mathrm{RAB}$ mix had a better fatigue life. The latter agrees with the conventional fatigue parameter $\varepsilon_{6}$. It must be noted here that the standard deviations for the three mixtures are overlapping. As a result, it can be speculated that the average values are not statistically different. However, this cannot be further statistically tested because of the limited number of replicates.

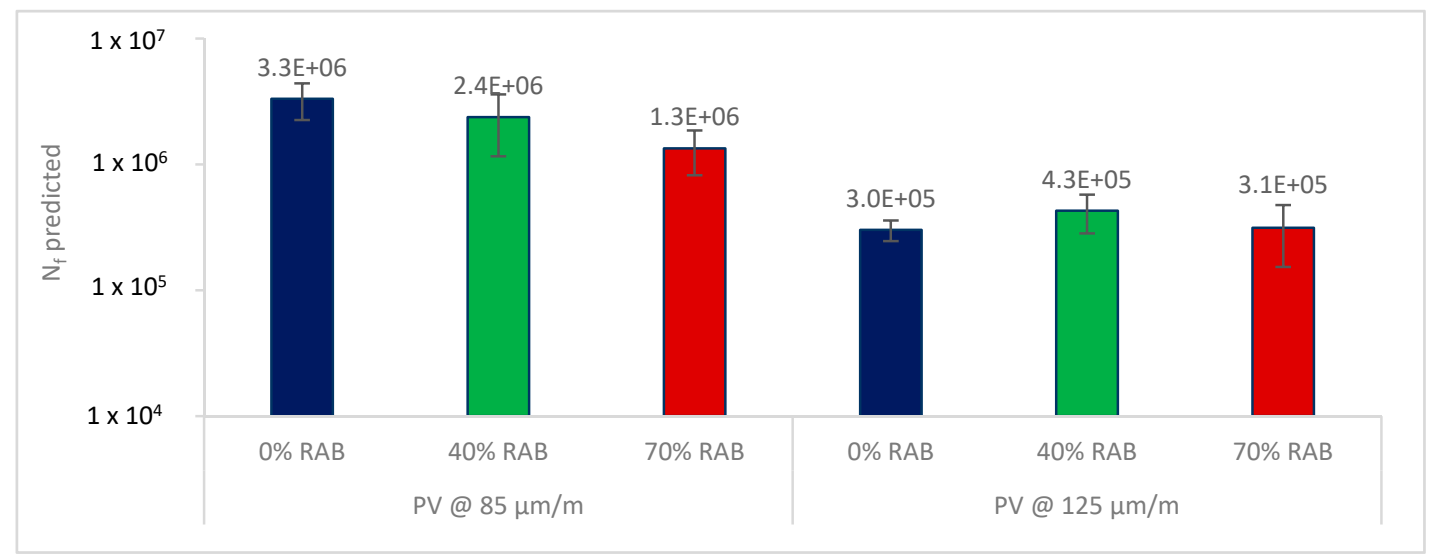

Figure 7. Predicted fatigue life of the asphalt scale, per mixture, for the two strain levels based on the PV (Equation (4)).

\subsection{Bituminous Mortars}

Figure 8 shows the $\left|\mathrm{G}^{*}\right|$ for the mortar samples, tested at $15^{\circ} \mathrm{C}$ and $10 \mathrm{~Hz}$. Prior to fatigue testing, the mortar samples were tested at a low stress level within the LVER $(0.001 \mathrm{MPa})$ in order to measure the $\left|G^{*}\right|$ of the mortar samples. The results show that the $0 \%$ RAB mortar mix has the highest $\left|G^{*}\right|$, followed by the $40 \%$ and $70 \%$ mixes. Unlike the asphalt mixture results where the three mixtures demonstrated similar modulus, the mortar mixtures with $40 \%$ and $70 \%$ RAB showed a lower modulus on the mortar scale. Finally, the addition of a different filler type in the $40 \%$ and $70 \%$ RAB mortar mixes, i.e., the one coming from the RA, seems to have no impact on the measured $\left|G^{*}\right|$, since these results follow the results of the measured penetration for the three final binder blends with $0 \%, 40 \%$, and $70 \%$ RAB. 


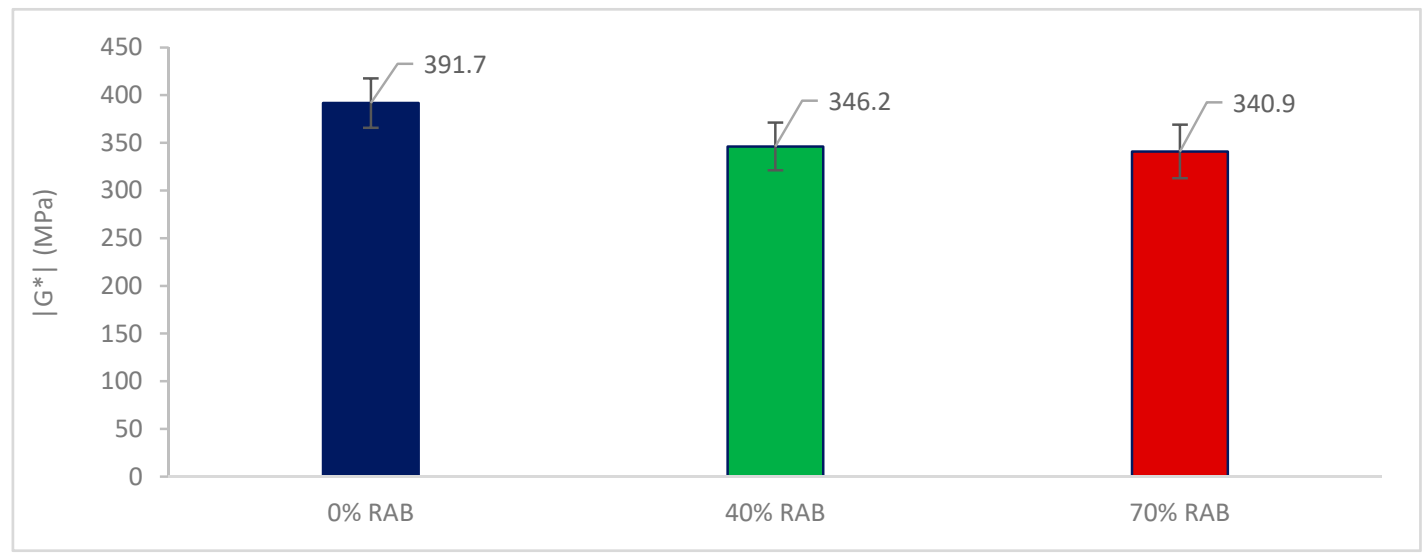

Figure 8. $\left|\mathrm{G}^{*}\right|$ at $15^{\circ} \mathrm{C}$ and $10 \mathrm{~Hz}$ for the three mortar mixes.

Next, the fatigue results of the phenomenological approach are depicted in Figure 9, and the regression parameters of the fatigue lines are shown in Table 6. According to the $\mathrm{N}_{\mathrm{f}, \mathrm{G}^{*} \mathrm{xC}}$ criterion, the inclusion of $\mathrm{RAB}$ leads to a decrease in fatigue life, and hence the all-virgin mortar $(0 \% \mathrm{RAB})$ exhibits the highest fatigue resistance. The results of the mortar scale seem to be strongly influenced by the stiffness of the samples, as they follow the same ranking as the $\left|G^{*}\right|$ of the mortar samples.

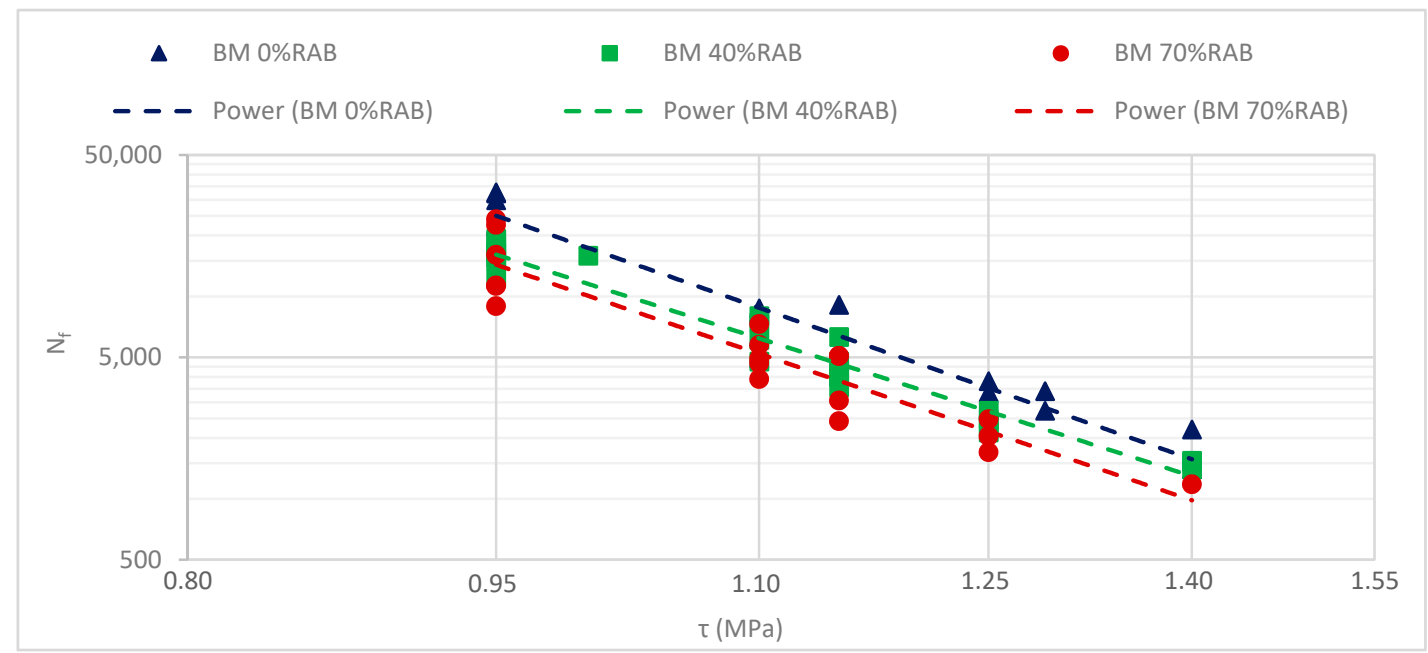

Figure 9. Fatigue curves of the three bituminous mortar mixtures, based on the $\mathrm{N}_{\mathrm{f}, \mathrm{G}^{*} \mathrm{xC}}$ criterion .

Table 6. Fatigue test parameters of tested mortar mixtures.

\begin{tabular}{cccc}
\hline $\mathbf{N}_{\mathbf{f}, \mathbf{G x C}}=\mathbf{A}(\boldsymbol{\tau})^{\mathbf{B}}$ & $\mathbf{A}$ & $\mathbf{B}$ & $\mathbf{R}^{\mathbf{2}} \mathbf{( \% )}$ \\
\hline APO-B 0\% RAB & 17377 & -7.143 & 94.15 \\
APO-B 40\% RAB & 11545 & -6.498 & 95.46 \\
APO-B 70\% RAB & 10078 & -6.912 & 88.06 \\
\hline
\end{tabular}

The $\mathrm{N}_{\mathrm{f}, \mathrm{G}^{*} \mathrm{xC}}$ fatigue results are not in line with the results of the asphalt-scale fatigue tests, according to which the $40 \%$ RAB mix exhibited the highest fatigue resistance based on the conventional fatigue criterion $\varepsilon_{6}$. However, attempting to relate the two scales should be done with care, considering the specific differences between them.

Firstly, the failure type between the two scales is different. For the asphalt scale, both adhesive and cohesive failure may take place, whereas in the mortar scale, only the resistance against cohesive failure is considered. In fact, due to the presence of the fine particles, this failure mode can also be considered as semicohesive, since the loss of adhesion between the bituminous binder and the fine 
particles may also occur. However, since it is regarded as one phase that covers and bonds the coarse skeleton, the primary failure type that drives this phase (i.e., the mortar) to fail is considered to be cohesive. Secondly, the deformation mode is different; the mortar samples are deformed in shear mode while asphalt samples are in tension-compression. Finally, the two scales were tested under a different loading mode, namely the asphalt-scale tests under strain control and the mortar under stress.

Nevertheless, a linear relationship can be obtained between the slopes of the fatigue tests, as depicted in Figure 10. To further support this relationship, more tests are necessary as well as the consideration of different materials. Finally, the effect of the enriched binder content should be investigated in more depth to further solidify the relationship to the asphalt scale.

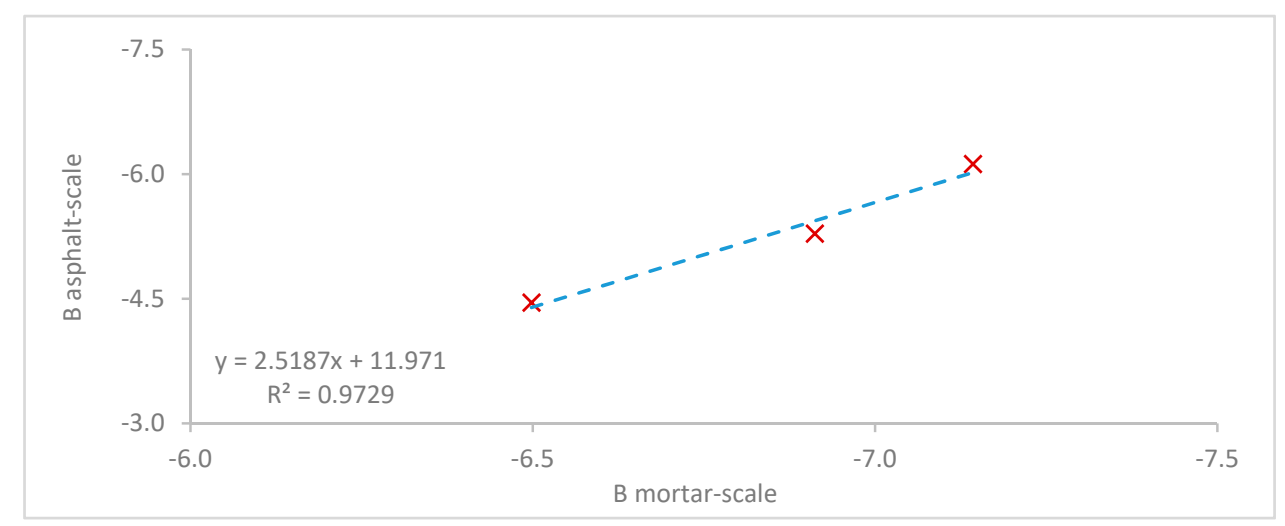

Figure 10. Relationship between the slopes (B) derived from the mortar- and the asphalt-scale fatigue tests.

The fatigue resistance of mortars was further evaluated using the energy concepts of DER and RDEC. In an earlier study concerning the fatigue characterisation of mortars, it was found that the DER approach led to a fatigue model that was independent of temperature but dependent on the bitumen type (modified or not) [23]. Figure 11 presents the result of the DER approach for the studied mortar samples. Here, a unified model was derived, which was expected since none of the mortars contained a polymer-modified binder (PMB).

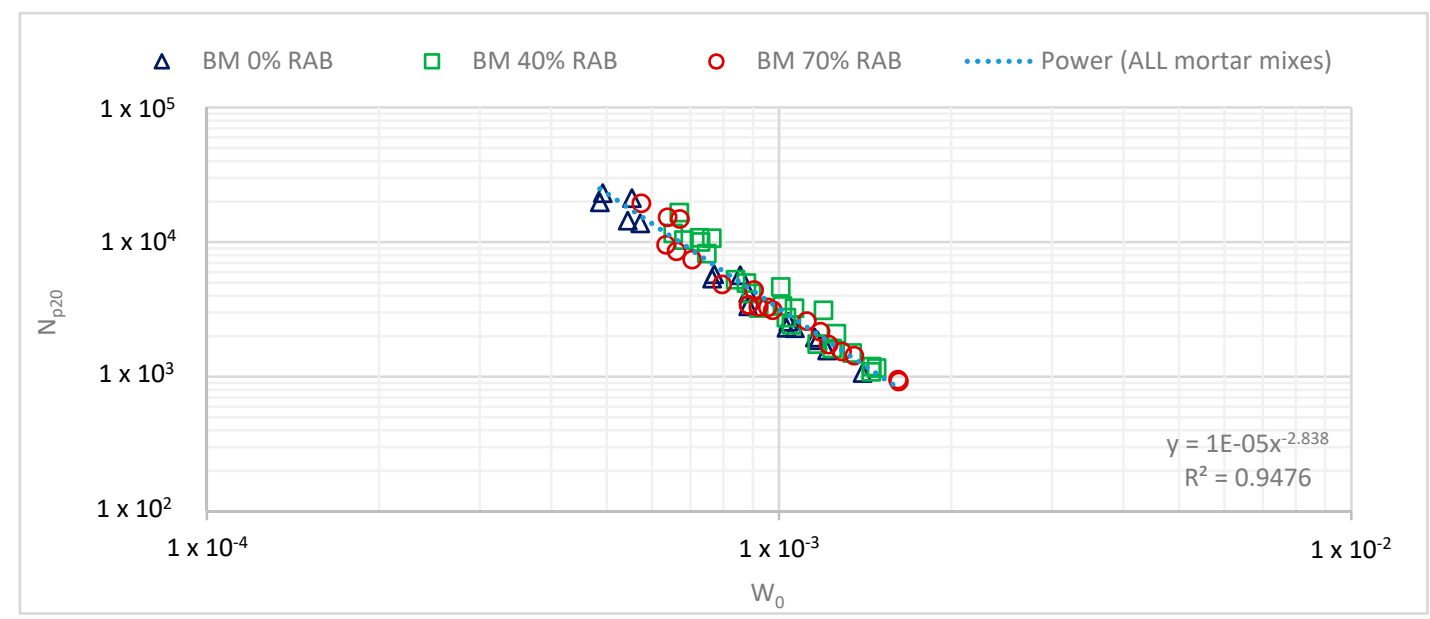

Figure 11. Fatigue resistance of mortars, based on the DER approach $\left(\mathrm{N}_{\mathrm{p} 20}\right)$.

The obtained $\mathrm{N}_{\mathrm{p} 20}$ for every tested mortar sample was used together with the findings of the RDEC approach. Figure 12 illustrates the unified fatigue model, using the results of the $0 \%, 40 \%$, and $70 \%$ RAB mortar mixtures. Furthermore, extra mortar samples (presented in a previous study [23]) were additionally considered, i.e., mortars containing PMB and mortars tested at different temperatures 
(different than $15{ }^{\circ} \mathrm{C}$ ) as well as different loading modes, thus leading to an even more robust fatigue model.

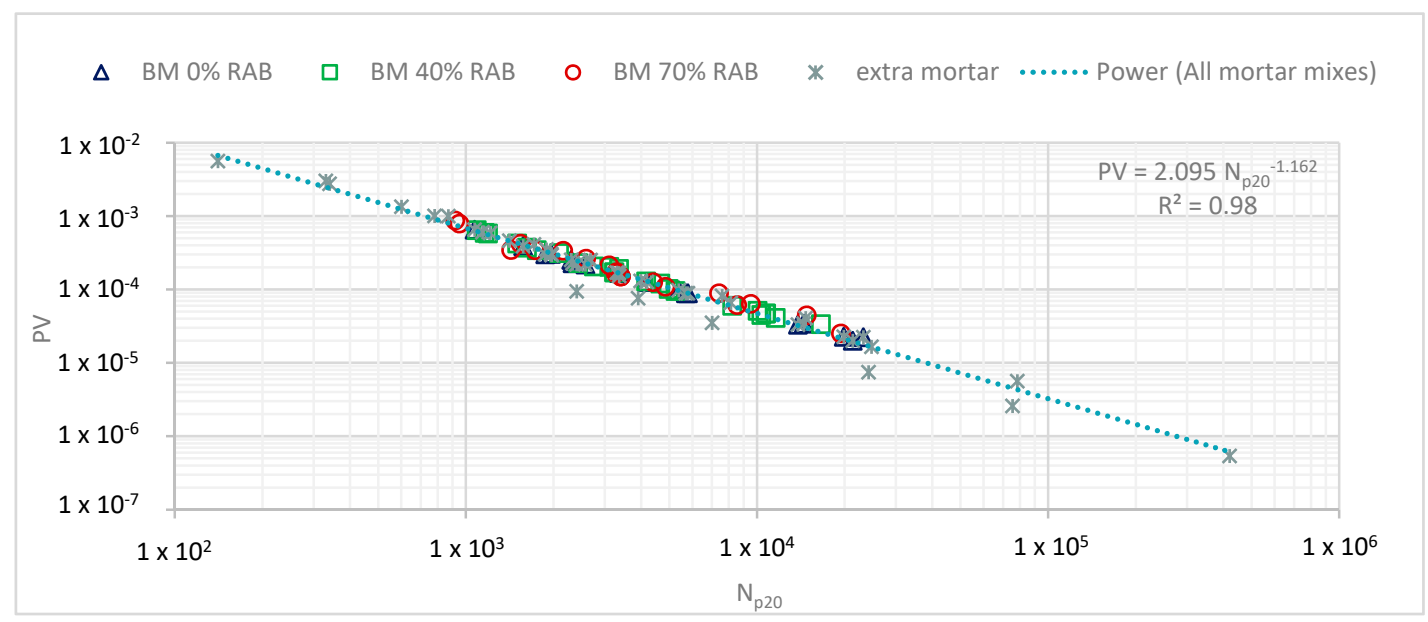

Figure 12. Fatigue resistance of the mortars for the three replacement rates of $0 \%, 40 \%$, and $70 \%$ RAB based on the RDEC approach: Np20 vs. PV. The extra mortar points were derived from a previous study [23].

Following the same approach as for the fatigue tests performed in the asphalt scale, two tested stress levels were selected to represent two structural scenarios: the 0.95 and $1.25 \mathrm{MPa}$, representing a thick layer and thin layer, respectively. The two stress levels were the lowest and highest tested stress levels with at least 3 repetitions. Rearranging the resulted fit of Figure 12, a new fatigue model is derived for the three mortars that is able to estimate the $\mathrm{N}_{\mathrm{f}}$ for a given PV (Equation (5)).

$$
\mathrm{N}_{\mathrm{f}}=2.1982 \mathrm{PV}^{-0.844}
$$

For every single PV value, the corresponding $\mathrm{N}_{\mathrm{f}}$ was calculated using Equation (5). The average predicted $\mathrm{N}_{\mathrm{f}}$ values are illustrated in Figure 13 per mortar and stress level. For both layer structures (thicker and thinner layer), the $0 \%$ RAB mix showed the highest fatigue resistance, as this was also demonstrated based on the $\mathrm{N}_{\mathrm{f}, \mathrm{G}^{*} \mathrm{xC}}$ approach. Similarly to the asphalt scale results, the predicted $\mathrm{N}_{\mathrm{f}}$ exhibited overlapping standard deviations, which possibly indicates nonsignificant differences among the average values. This cannot be further statistically verified as it requires a larger number of replicates.

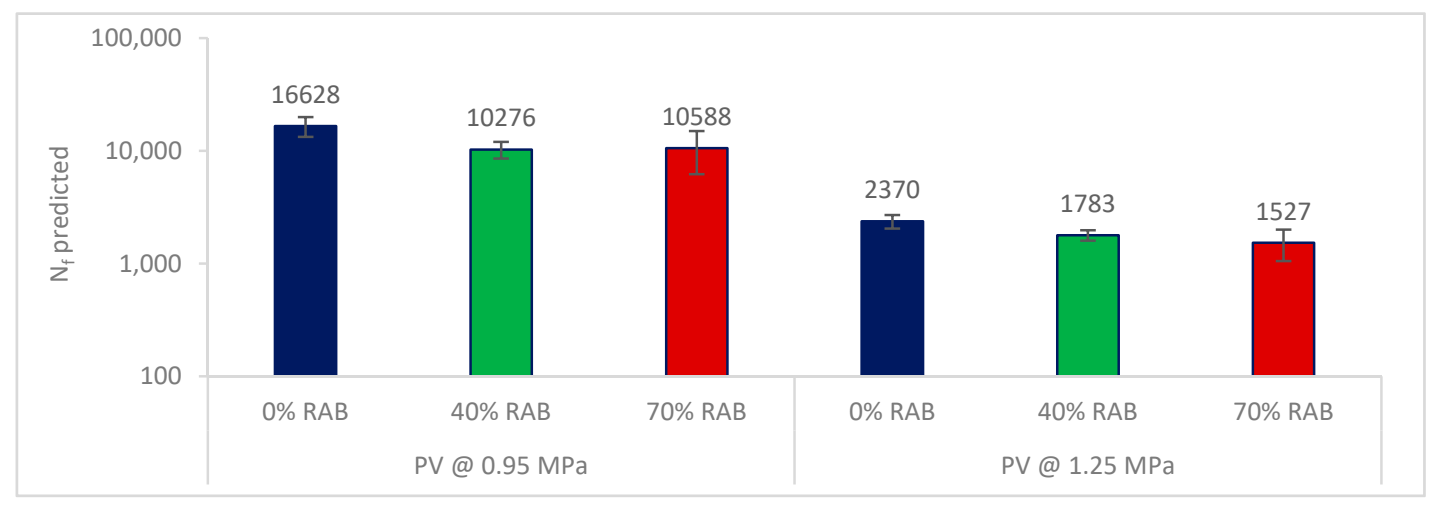

Figure 13. Predicted fatigue life of the mortar scale, per mixture, for the two stress levels based on the PV (Equation (5)). 
The ranking of the estimated fatigue life was similar to the one derived from the asphalt scale for the thick-layer case (PV at $85 \mu \mathrm{m} / \mathrm{m}$ ). For the higher stress level of $1.25 \mathrm{MPa}$, the mortar fatigue is more severe for the samples with lower $\left|G^{*}\right|$, i.e., the samples with $40 \%$ and $70 \% \mathrm{RAB}$, showing the lowest fatigue resistance. One of the disadvantages of a stress-control test is that the samples may fail due to excessive creep deformation, and hence a "softer" sample will exhibit lower fatigue resistance. Yet, issues may also appear with strain-control tests, with one possibly observed in this study being that stiffer samples may perform better.

To avoid creep and viscoelastic flow, a possible strategy that may tackle this issue is performing the tests at a lower temperature (lower than $15^{\circ} \mathrm{C}$ ), low enough to make sure that the sample is more in its elastic region $\left(\delta<45^{\circ}\right)$. Testing the sample at a temperature condition that results in a behaviour closer to its viscous region $\left(\delta>45^{\circ}\right)$ may lead the sample to fail predominately due to flow $[39,40]$. Lowering the binder content can also overcome this issue, making the mortar sample stiffer, but care should be taken that the samples are workable enough. Nevertheless, a balanced temperature selection should be respected, where the temperature should be low enough to ensure elastic behaviour but also high enough so that it belongs in the intermediate temperature regime, where fatigue cracking is expected to occur.

Comparing the two scales, mortar and asphalt, there is no consensus concerning which RAB replacement rate will perform better in fatigue. The difference in ranking can be first explained by the blending of the RAB. In the mortar scale, the RAB blended fully with the virgin counterpart, whereas in bulk scale, the results pointed out that especially for the $70 \% \mathrm{RAB}$, there was lower RAB activity and thus lower blending efficiency. A second parameter that may affect the results, and consequently the ranking, is the mechanism that drove the mortar samples to failure at higher stress levels, which may be attributed to creep deformation, a failure mechanism not expected for the much stiffer asphalt samples. Evaluating the fatigue resistance of mixtures containing RA, the bulk scale (asphalt) is still the best approach to assess fatigue. Two main reasons are, first, that partial blending is most likely expected to occur and, second, the fact that fatigue can be initiated due to both cohesive and adhesive failure. The current fatigue mortar testing does not consider these aspects.

\section{Conclusions and Recommendations}

In this study, the effect of a RAB on the fatigue resistance of bituminous mortars and mixtures was investigated. Three mortar and asphalt mixtures, containing three RAB replacement rates $0 \%$, $40 \%$, and $70 \%$, were assessed. Based on this investigation, the following conclusions were drawn concerning the two main objectives: the effect of a RAB on the fatigue resistance of asphalt mixtures and mortars and the effectiveness of only treating them with a virgin binder.

Concerning the impact of a RAB on the fatigue resistance:

- For the asphalt scale, following the $\varepsilon_{6}$ rule, the $40 \%$ RAB mix performed better compared to the other mixtures. Based on the PV approach, the same asphalt mix (40\% RAB) showed the highest fatigue resistance for the $125 \mu \mathrm{m} / \mathrm{m}$ level. In contrast, it changed at the $85 \mu \mathrm{m} / \mathrm{m}$ level, where the $0 \%$ RAB mix showed the highest fatigue resistance.

- For the mortar scale, the samples with more RAB yielded lower fatigue life, as exhibited by both conventional and energy approaches.

Concerning the effectiveness of the selected RAB treatment strategy:

- Based on the results of the asphalt scale, adding only the virgin binder was an effective approach for the $40 \%$ RAB mix, but not for the $70 \%$ RAB mix, as demonstrated by the weaker fatigue resistance.

- On the other hand, based on the mortar scale results, adding only the virgin binder was not beneficial for the mortars containing a RAB. The fatigue results seemed to be strongly influenced by the $\left|G^{*}\right|$ of the mortar samples, which was lower for the $40 \%$ and $70 \%$ RAB mortar mix.

Generally, evaluating the fatigue resistance of mixtures containing RA, the bulk scale (asphalt) is still the best approach to assess fatigue. The motivation is mainly that partial blending cannot be 
captured by the mortar tests, at least not when using the proposed testing method. Additionally, fatigue can occur due to both cohesive and adhesive failure, and the current fatigue mortar testing considers only the former. However, mortar fatigue tests are useful alternative tests for preliminary evaluation instead of performing binder fatigue tests.

The results of this study should be further validated for different RA types and with different treatment strategies (e.g., use of rejuvenators). Concerning the considered analysis methods, the RDEC approach is a promising alternative to assess fatigue resistance, as it has the advantage of being independent of material and testing conditions. However, the disadvantage of this method is that it requires an extended postprocessing effort. For the fatigue characterisation of mortars, certain adjustments were performed on the bitumen content to achieve a workable bituminous mortar mixture. This may influence the fatigue results; therefore, this factor needs further validation. A leaner mortar mixture may be a better representation of the actual mortar scale; however, that will require compaction aid to achieve a good mortar mixture.

Author Contributions: Conceptualization, A.M. and W.V.d.b.; methodology, A.M.; formal analysis, A.M. and G.P.; investigation, A.M. and G.J. ; resources, G.J. and J.B.; writing-original draft preparation, A.M.; writing-review and editing, A.M., G.P., G.J., J.B., and W.V.d.b.; supervision, J.B. and W.V.d.b. All authors have read and agreed to the published version of the manuscript.

Funding: This research received no external funding.

Acknowledgments: The first author would like to acknowledge the University of Antwerp for the doctoral funding. Additionally, the authors would like to acknowledge Willemen Infra, Holcim, and Nynas for the provided material.

Conflicts of Interest: The authors declare no conflict of interest.

\section{References}

1. Margaritis, A.; Blom, J.; Van den bergh, W. Evaluating the mechanical performance of Flemish bituminous mixtures containing RA by statistical analysis. Road Mater. Pavement Des. 2019, 20, S725-S739. [CrossRef]

2. Anthonissen, J. Bituminous Pavements in Flanders: Quantifying the Effect of RAP on the Environmental Impact; University of Antwerp: Antwerp, Belgium, 2017.

3. Zaumanis, M.; Mallick, R.B. Review of very high-content reclaimed asphalt use in plant-produced pavements: State of the art. Int. J. Pavement Eng. 2015, 16, 39-55. [CrossRef]

4. Newcomb, D.E.; Brown, E.R.; Epps, J.A. Designing HMA Mixtures with High RAP Content: A Practical Guide; National Asphalt Pavement Association: Landam, MD, USA, 2007; p. 36.

5. Al-Qadi, I.L.; Aurangzeb, Q.; Carpenter, S.H.; Pine, W.J.; Trepanier, J. Impact of High RAP Contents on Structural and Performance Properties of Asphalt Mixtures; Illinois Center for Transportation: Springfield, IL, USA, 2012.

6. Tarsi, G.; Tataranni, P.; Sangiorgi, C. The Challenges of Using Reclaimed Asphalt Pavement for New Asphalt Mixtures: A Review. Materials 2020, 13, 4052. [CrossRef]

7. Huang, Y.H. Pavement Analysis and Design Prentice Hall; Prentice Hall PTR: Englewood Cliffs, NJ, USA, 1993; p. 785.

8. Copeland, A. Reclaimed Asphalt Pavement in Asphalt Mixtures: State of the Practice; Federal Highway Administration. Office of Research, Development, and Technology: McLean, VA, USA, 2011; p. 60.

9. West, R.; Michael, J.; Turochy, R.; Maghsoodloo, S. Use of Data from Specific Pavement Studies Experiment 5 in the Long-Term Pavement Performance Program to Compare Virgin and Recycled Asphalt Pavements. Transp. Res. Rec. 2011, 2208, 82-89. [CrossRef]

10. Zaghloul, S.; Holland, T.J. Comparative Analysis of Long-Term Field Performance of Recycled Asphalt in California Environmental Zones. Transp. Res. Rec. 2008, 2084, 83-99. [CrossRef]

11. McDaniel, R.S.; Shah, A.; Huber, G. Investigation of Low-and High-Temperature Properties of Plant-Produced RAP Mixtures; Federal Highway Administration. Office of Pavement Technology: McLean, VA, USA, 2012; p. 107.

12. Sabouri, M.; Bennert, T.; Sias Daniel, J.; Richard Kim, Y. A comprehensive evaluation of the fatigue behaviour of plant-produced RAP mixtures. Road Mater. Pavement Des. 2015, 16, 29-54. [CrossRef] 
13. Mangiafico, S.; Di Benedetto, H.; Sauzeat, C.; Olard, F.; Dupriet, S.; Planque, L.; Van Rooijen, R. Effect of reclaimed asphalt pavement on complex modulus and fatigue resistance of bitumens and asphalts. In Proceedings of the 5th Eurasphalt \& Eurobitume Congress, Istanbul, Turkey, 13-15 June 2012; p. 10.

14. Riccardi, C.; Cannone Falchetto, A.; Wistuba, M.P.; Losa, M. Fatigue comparisons of mortars at different volume concentration of aggregate particles. Int. J. Fatigue 2017, 104, 416-421. [CrossRef]

15. Kim, Y.-R.; Little, D.N.; Song, I. Effect of Mineral Fillers on Fatigue Resistance and Fundamental Material Characteristics: Mechanistic Evaluation. Transp. Res. Rec. 2003, 1832, 1-8. [CrossRef]

16. Margaritis, A.; Tofani, G.; Jacobs, G.; Blom, J.; Tavernier, S.; Vuye, C.; Van den bergh, W. On the Applicability of ATR-FTIR Microscopy to Evaluate the Blending between Neat Bitumen and Bituminous Coating of Reclaimed Asphalt. Coatings 2019, 9. [CrossRef]

17. Kim, S.; Roque, R.; Guarin, A.; Birgisson, B. Identification and assessment of the dominant aggregate size range (dasr) of asphalt mixture (with discussion). J. Associ. Asphalt Paving Technol. 2006, 75, 789-814.

18. EN 1426. Bitumen and Bituminous Binders Determination of Needle Penetration; Bureau voor Normalisatie: Brussels, Belgium, 2015.

19. EN 1427. Bitumen and Bituminous Binders-Determination of the Softening Point_Ring and Ball Method; Bureau voor Normalisatie: Brussels, Belgium, 2015.

20. Margaritis, A.; Soenen, H.; Fransen, E.; Pipintakos, G.; Jacobs, G.; Blom, J.; Van den bergh, W. Identification of ageing state clusters of reclaimed asphalt binders using principal component analysis (PCA) and hierarchical cluster analysis (HCA) based on chemo-rheological parameters. Constr. Build. Mater. 2020, 244, 118276. [CrossRef]

21. EN 12697-5. Bituminous Mixtures-Test Methods_Part 5: Determination of the Maximum Density; Bureau voor Normalisatie: Brussels, Belgium, 2018.

22. EN 12697-35. Bituminous Mixtures-Test Methods for Hot Mix Asphalt. Part 35: Laboratory Mixing; Bureau voor Normalisatie: Brussels, Belgium, 2016.

23. Margaritis, A.; Pipintakos, G.; Varveri, A.; Jacobs, G.; Hasheminejad, N.; Blom, J.; Van den bergh, W. Towards an enhanced fatigue evaluation of bituminous mortars. Constr. Build. Mater. 2020, 121578. (In Press) [CrossRef]

24. EN 13108-1. Bituminous Mixtures Material Specifications_Part 1: Asphalt Concrete; Bureau voor Normalisatie: Brussels, Belgium, 2016.

25. EN 12697-26. Bituminous Mixtures-Test Methods for Hot Mix Asphalt. Part 26: Stiffness; Bureau voor Normalisatie: Brussels, Belgium, 2018.

26. EN 12697-24. Bituminous Mixtures Test Methods for Hot Mix Asphalt. Part 24: Resistance to Fatigue; Bureau voor Normalisatie: Brussels, Belgium, 2018.

27. Ghuzlan, K.A.; Carpenter, S.H. Energy-Derived, Damage-Based Failure Criterion for Fatigue Testing. Transp. Res. Rec. 2000, 1723, 141-149. [CrossRef]

28. Carpenter, S.H.; Shen, S. Dissipated Energy Approach to Study Hot-Mix Asphalt Healing in Fatigue. Transp. Res. Rec. 2006, 1970, 178-185. [CrossRef]

29. Shen, S.; Airey, G.D.; Carpenter, S.H.; Huang, H. A Dissipated Energy Approach to Fatigue Evaluation. Road Mater. Pavement Des. 2006, 7, 47-69. [CrossRef]

30. Rowe, G.M.; Bouldin, M.G. Improved techniques to evaluate the fatigue resistance of asphaltic mixtures. In Proceedings of the 2nd Eurasphalt \& Eurobitume Congress, Barcelona, Spain, 20-22 September 2000; p. 10.

31. Subhy, A.; Lo Presti, D.; Airey, G. New simplified approach for obtaining a reliable plateau value in fatigue analysis of bituminous materials. Eng. Fail. Anal. 2017, 79, 263-273. [CrossRef]

32. Islam, M.R.; Tarefder, R.A. Study of Asphalt Aging through Beam Fatigue Test. Transp. Res. Rec. 2015, 2505, 115-120. [CrossRef]

33. Perez-Martinez, M.; Marsac, P.; Gabet, T.; Hammoum, F.; de Mesquita Lopes, M.; Pouget, S. Effects of Ageing on Warm Mix Asphalts with High Rates of Reclaimed Asphalt Pavement. In Proceedings of the 8th RILEM International Conference on Mechanisms of Cracking and Debonding in Pavements, Dordrecht, The Netherlands, 7-9 June 2016; pp. 113-118.

34. Kim, M.; Mohammad, L.N.; Jordan, T.; Cooper, S.B. Fatigue performance of asphalt mixture containing recycled materials and warm-mix technologies under accelerated loading and four point bending beam test. J. Clean. Prod. 2018, 192, 656-664. [CrossRef] 
35. Mangiafico, S.; Sauzéat, C.; Di Benedetto, H.; Pouget, S.; Olard, F.; Planque, L.; van Rooijen, R. Statistical Analysis of Influence of Mix Design Parameters on Mechanical Properties of Mixes with Reclaimed Asphalt Pavement. Transp. Res. Rec. 2014, 2445, 29-38. [CrossRef]

36. Zaumanis, M.; Mallick, R.B. Finite Element Modeling of Rejuvenator Diffusion in RAP Binder Film-Simulation of Plant Mixing Process; Springer: Dordrecht, The Netherlands, 2013; pp. 407-419.

37. Ding, Y.; Huang, B.; Shu, X.; Zhang, Y.; Woods, M.E. Use of molecular dynamics to investigate diffusion between virgin and aged asphalt binders. Fuel 2016, 174, 267-273. [CrossRef]

38. Zaumanis, M.; Poulikakos, L.D.; Partl, M.N. Performance-based design of asphalt mixtures and review of key parameters. Mater. Des. 2018, 141, 185-201. [CrossRef]

39. Shan, L.; Tian, S.; He, H.; Ren, N. Internal crack growth of asphalt binders during shear fatigue process. Fuel 2017, 189, 293-300. [CrossRef]

40. Safaei, F.; Castorena, C. Temperature Effects of Linear Amplitude Sweep Testing and Analysis. Transp. Res. Rec. 2016, 2574, 92-100. [CrossRef]

Publisher's Note: MDPI stays neutral with regard to jurisdictional claims in published maps and institutional affiliations.

(C) 2020 by the authors. Licensee MDPI, Basel, Switzerland. This article is an open access article distributed under the terms and conditions of the Creative Commons Attribution (CC BY) license (http://creativecommons.org/licenses/by/4.0/). 